Cilt: 5, Sayı: 2, 2021; 163-174

E-ISSN: 2587-134X

URL: http://dergipark.org.tr/usbd

\title{
Metaverse Evreninde Sporun Bugünü ve Geleceğine Yönelik Bir Derleme
}

\author{
Naci KALKAN ${ }^{*}$ \\ ${ }^{1}$ Manisa Celal Bayar Üniversitesi, Spor Bilimleri Fakültesi.
}

Derleme

Gönderi Tarihi: 23.11.2021
Kabul Tarihi: 29.12.2021
DOI:10.30769/usbd.1027728

Online Yayın Tarihi: 31.12.2021

\section{$\ddot{O} \mathbf{z}$}

Sanal ve ikiz dünyalarda etkileşim ve alternatif bir dünya yaratma fikrinin kavramsal açıdan tezahürü olan Metaverse, gelişen teknolojinin desteğiyle günümüzde adına sıkça rastladığımız bir fenomen haline gelmiştir. İnternet ötesine dair bir fikir olan bu kavram, insanlara zaman, mekan, yer kısıtları nedeniyle gerçekleştiremediği deneyimlerden, sınırsız bir gerçekliğe kadar uçsuz bir ortamı vaad etmektedir. Birçok alanda sanal gerçeklik ve Metaverse kavramının ilişkisine dair akademik makalelere, ticari faaliyetlere rastladığımız bugünlerde, spor gibi güçlü rekabet özellikleri olan devasa bir endüstrinin bu gelişmelerden uzakta kalamayacağı da aşikardır. Bu çalışma genel olarak Metaverse kavramına, kavramın spor olgusuyla ilişkisine ve geleceğine dair çıkarımlara odaklanmayı amaçlamaktadır.

Anahtar kelimeler: Metaverse, spor, sanal gerçeklik, ikiz dünyalar.

\section{A Compilation of the Present and Future of Sports in the Metaverse Universe}

\begin{abstract}
Metaverse, which is the conceptual manifestation of the idea of interaction and creating an alternative world in virtual and twin worlds, has become a phenomenon that we frequently encounter today with the support of developing technology. The notion which reaches beyond the internet, promises an unlimited area to an endless reality that people could not accomplish their experiences due to time, place and environment limitations.Also, it is certain that, a huge industry which has strong competitive features like sports can not stay distant from these developments especially the days we come across with academic articles and commercial activities on the relationship between the concept of Metaverse and virtual reality in many fields. This study aims to focus on the current relationship and future of the concept of Metaverse with sports.
\end{abstract}

Keywords: Metaverse, sport, virtual reality, twin worlds.

\footnotetext{
* Sorumlu yazar: Naci KALKAN, E-Posta: kalkannaci@ hotmail.com
} 


\section{GíRiş}

28 Ekim 2021 tarihinde Facebook'un kurucusu Mark Zuckerberg'in, şirketlerini Meta isimli bir çatı firmada birleştireceğine ve Metaverse alanına 10 Milyar Dolarlık bir yatırım yapacağını yönelik açılaması dünya gündeminde günler boyu üst sıralarda yer almıştır (Zuckerberg \& Heath, 2021). Bilim ve toplum nezninde çok bilinirliği olmayan Metaverse kavramının bu boyutta ele alınması, yoğun bir ilgiyi de üzerine çekmesine sebep olmuştur. Metaverse kavramıyla yeni tanışan birçok kişinin aksine bu kavramın doğuşunun Neal Stephenson'un Snow Crash (1992) isimli bilim kurgu kitabında ilk kez bahsettiği 1992 yılına dayandığını ve Metaverse evreninin en önemli aracı olan sanal gerçeklik sistemlerinin 100 yılı aşan bir geçmişe sahip olduğunu, Metaverse'de bugün nerede olduğumuzu, sporun bu kavramdaki yerini ve yarınını ele almaktadır.

Metaverse kavramı genel olarak, insanlara sanal gerçeklik (SG) ortamı oluşturmak için başa takılan ekran aracılı̆̆ıla, sürükleyici bir deneyimle alternatif bir sanal dünyada oynamasına, çalışmasına ve sosyalleşmesine olanak tanıyan yeni nesil İnternet paradigması olarak kabul edilir (Dionisio, Burns, \& Gilbert, 2013; Dionisio, III, \& Gilbert, 2013; Sparkes, 2021). Bir diğer ifadeyle, ayrımının altının güçlü bir şekilde çizilmesi gerekliliğiyle, "sürükleyici" bir 3 boyutlu sanal ortamda avatarların kullanıcının ikinci kişiliği olarak hareket ettiği ve diğer kullanıcilarla etkileşime geçtiği gerçekçi bir sanal platformdur (Lee, Braud, Zhou, Wang, Xu, Lin \& Hui, 2021; Nevelsteen, 2018). Metaverse, aşkınlık anlamına gelen 'meta' ve gerçek dünya anlamına gelen 'evren' kelimelerinin birleşik bir kelimesidir (Sparkes, 2021). Mevcut sanal gerçeklikten daha geniş bir kavram olarak yorumlanabilir. Özellikle Covid-19 pandemisi sebebiyle birçok alanda çevrimiçi alternatiflerin oluştuğu bir dönemde bu internet ötesi kavramın popülerliğinin artması ve çeşitli yatırımlarla desteklenmesi de önem düzeyini artırmaktadır (Jeon, Youn, Ko, \& Kim, 2021). Özellikle gerçek gibi noktasından bilişsel gerçekliğe tam uygunlaşma evresinin sınırsız bir dünya düzenine olanak sağlayabileceği söylenebilir. Öyle ki, Metaverse evreninde avatarları aracıllğıyla ticaret yapılabilmesi, sanat gibi bir olgunun NFT (Non-fungible Token) ismi verilen dijitalize eserler aracılığılla sergilenebilmesi ve alınıp satılabilmesi, alışveriş yapılabilmesi ve hatta konser ve spor müsabakalarında oradaymışçasına seyirci olarak katılabilme olanakları sunabilmesine geçtiğimiz birkaç senede şahit olduk (Cannavo \& Lamberti, 2021). Bu bahsedilenlere örnek olarak Joe Biden'ın Amerika Birleşik Devletleri seçim kampanyasında Nintendo'nun ‘Animal Crossing' etkinliğinde kampanya yürütmesi, Güney Kore'de ünlü bir KPOP grubunun yeni şarkılarını çevrimiçi bir oyun olan Portlight'da ilk kez seslendirmiş olmaları, Travis Scott'ın çevrimiçi konserine 13 Milyon kişinin katılım sağlaması ve Blackpink'in çevrimiçi imza törenine 50 Milyon kişinin katılım sağlaması örnek olarak verilebilir (Cannavo \& Lamberti, 2021). Bunun yanında öğretimin her kademesinde bir metot olarak kullanıldığına ve etkinliğinin ortaya konduğuna yönelik birçok bilimsel çalışma da bulunmaktadır (Elmqaddem, 2019; González-Zamar \& Abad-Segura, 2020; Kavanagh, Luxton-Reilly, Wuensche, \& Plimmer, 2017). Özetle Metaverse kavramı, spordan, sanata, eğitimden ticarete hayatımızın birçok alanında yoğun olmasa da güçlü bir şekilde yer almaya başlamış ve her geçen gün etki alanını büyütmeye başlamıştır. 
Metaverse evreninin tarihine bakmak, kavramı daha etkili bir biçimde tanımamıza olanak sağlayabilecektir. Metaverse kavramı ilk kez 1992 Neal Stephenson tarafından dile getirilmiş olsa da tarihsel kökeni kavramı oluşturmaya daha önceden başlamıştır. Metaverse kavramının tarihi adımları aşağıdaki şekilde sıralanabilir.

- 1974 - Dungeons \& Dragons kitabında edebi bağlamda sanal dünyaların ele alınmas1

- 1984 - Neuromancer kitabında edebi bağlamda sanal dünyaların ele alınması

- 1987 - Bilgisayarların yayılmasını takriben yazı temelli interaktif oyunların ilk örneği AberMUD'un yayımlanmasi

- $\quad$ 1990- Yazı temelli interaktif oyun DikuMUD’un yayımlanması

- 1992- Metaverse kavramının ilk kez ortaya konduğu Snow Crash kitabının yayımlanmasi

- $\quad$ 1995- Sanal dünya yaratımının başladığı, çevrimiçi ve çoklu oyunculu oyunların piyasa çıkış1.

- $\quad$ 1995- Sanal dünya yaratımının ilk örneği Active World oyununun yayımlanması.

- $\quad$ 1996- Online Traveler oyunun yayımlanmasi

- 2003- Second Life isimli sanal dünyada avatar vasıtasıyla ikiz dünya yaratımı

- $\quad$ 2011- Çıktığı günden bu yana milyonlarca kişi tarafından oynanan Minecraft oyununun piyasaya çıkışı

- $\quad$ 2016- Fenomen çizgi dizi Pokemon'un sanal ikizi Pokemon Go oyununun artırılmış gerçeklik destekli sürümünün piyasaya çıkışı

- 2017- VR Chat isimli sosyalleşme platformunun sanal gerçeklik sistemleriyle entegrasyonu

- 2020- Oyna-Kazan temelli, Blockchain entegrasyonuyla donatılmış oyunların yaratımı

- 2021 ve günümüz, dev şirketlerin sanal gerçeklik ile ilgili yatırımlarını artırarak VR-

Metaverse boyutunda ARGE ve ÜRGE çalışmalarına başlaması, Metaverse'ün tarihsel ilerlemesini özetlemektedir (Lee vd., 2021).

$\mathrm{Bu}$ tarihsel dönemeçlerin temel olarak kavramın gelişimine yönelik ele alındığını ifade ederek, bu noktadan hareketle sanal gerçeklik ve metaverse ilişkisinden söz etmek gerekmektedir. Metaverse kavramının en basit tabirle, sanal dünyada internet ötesi ikiz bir yaşam sunmasına yönelik kurgusunda, gerçek dünyadan ayrışmayı sağlayacak araçlara ihtiyaç vardır. Bu araçlar, gerçekliğe yakınsama gücü olarak en güçlü sistemler olan sanal gerçeklik sistemleri ile mümkün olabilmektedir (Craig, Sherman, \& Will, 2009; Muñoz-Saavedra, Miró-Amarante, \& Domínguez-Morales, 2020). Sanal Gerçeklik; teknolojik donanımlar vasıtasıyla istenen ortamı gerçekçi biçimde dijital olarak kullanıcılara sunan, oluşturulan 3 boyutlu modeller üzerinde denetim hakkı tanıyan, duyusal açıdan gerçek hayata dair benzerlikleri hissettirebilen ve iki ayrı uçta bulunan yapay ile gerçek olgusu arasındaki yakınsamayı sağlayan sistemler olarak tanımlanabilir (Kalkan, 2020). Pratik uygulamanın yaygınlaşması ile sanal gerçeklik teknolojisi, inşaat, askeri, oyun ve eğitim gibi çeşitli alanlarda kullanılmaya başlanmıştır. Sanal gerçeklik temel olarak, gerçek dünyaya benzeşen ortamlar yoluyla bireylerin duyularını (görsel anlam, işitsel duyu, dokunsal duyu ve benzeri) simüle etmek için bilgisayar grafikleri, modern multimedya, yapay zekâ, kalıp tanıma, sensör ve diğer teknolojileri kapsamlı bir şekilde kullanır (Sivunen \& Nordbäck, 2015). 
Metaverse kavramının günümüzde önerdiği boyut, ikiz bir yaşamın sanal dünyada resmedilebilmesi ve burada çeşitli manipülasyonlara olanak sağlayarak, özgür bir öğrenme ve yaşama ortamı sunabilmesidir. Bu noktada sanal bir dünyanın insanlara 'gerçekçilik' boyutunda hissiyatın tam nakledilmesi günümüz teknolojisinde tam anlamıla mümkün olmasa da 'tam sürükleyici sanal gerçeklik sistemlerini' çeşitli alanlarda başarılı olduğu gerek sektörel anlamda gerekse de bilimsel anlamda birçok örnekle mevcuttur. Bu örneklerden bazıları aşağıda sunulmuştur.

- Emmelkamp ve Meyerbröker'in (2021) çalışmasında psikolojik sağlı için sanal gerçeklik terapisini başarılı şekilde uygulamaları,

- Hamilton ve diğerlerinin (2021) eğitimde sanal gerçeklik sistemlerinin başarıyla kullanımına dair çalışmaları, Bec ve diğerlerinin (2021) turizm sektörüne yönelik sanal gerçeklik sistemlerine yönelik çalışmaları,

- Arıcı'nın (2013) ilköğretim öğrencilerine Astronomi ünitesini sanal gerçeklik sistemleri aracılığıyla öğretimine yönelik olumlu sonuçlar aldığı çalışması,

- Topuz'un (2018) Tip Fakültesi öğrencilerine Anatomi dersinin sanal gerçeklik simülasyonları vasıtasıyla öğretimine yönelik olumlu sonuçlar aldığı çalışması,

- Ma ve diğerlerinin (2011) Parkinson hastalarında terapi yöntemi olarak sanal gerçeklik kullanımı,

- Smith ve diğerlerinin (2014) otistik çocuklarda sanal gerçeklik sistemlerinin etkinliğine yönelik çalışması,

- Webel ve diğerlerinin (2013) teknisyen eğitiminde sanal gerçeklik sistemlerinin etkinliğine dair çalışması,

- Wijkmark ve diğerlerinin (2021) itfaiye eğitiminde sanal gerçeklik sistemlerinin kullanımına yönelik çalışmaları,

- Egzersiz alanında Lee ve Kim (2018) tarafından yapılan sanal gerçekliğin vücut kompozisyonuna olumlu etkilerini sunduğu çalışmaları örnek olarak verilebilir.

Yukarıda sayılan ve bu konuda yapılmış birçok çalışma incelendiğinde, askeriye, eğitim, spor, turizm, oyun, tıp, astronomi gibi geniş bir yelpazede bu sistemlerin kullanıldığını gözlemlemekteyiz. Sanal gerçeklik sistemleri sürükleyicilik açısından üçe ayrılmaktadır. Bunlar tam sürükleyici sanal gerçeklik sistemleri, yarı sürükleyici sanal gerçeklik sistemleri ve sürükleyici olmayan sanal gerçeklik sistemleridir. Bu çalışmada ve günümüzde Metaverse dünyasında öne çıkartılan sanal gerçeklik sistemleri 'tam sürükleyici sanal gerçeklik sistemleridir' (Borges, Symington, Coltin, Smith, \& Ventura, 2018). Tam sürükleyici sanal gerçeklik sistemleri kullanıcıya 3 Boyutlu ortamlarda, kafaya monte başlıklar, kumandalar aracılığıyla tamamen sarmalayıcı özellikle çalışmaktadır. Bu özelliğii, kullanıcıyı dış dünyadan izole ederek, tamamen daldırmaya olanak sağlamaktadır (Dempsey, 2016). Bu noktada, bu sistemlerin neden avantaj sağladığının altını da çizmek gerekmektedir. Örneğin, astronomi konusunda, dünya dışı gezegenlerin videolar, basılı metinler ve çeşitli materyallerle anlatımının etkinliği ile sanal gerçeklik sistemleri vasıtasıyla sanki Ay'da, Mars'ta, Satürn'de, oradaymış̧̧asına dolaşabilme hissiyatının yaşanabilmesi arasında bir fark olduğu aşikardır. Günümüz teknolojisiyle dilediğimiz şekilde Ay'da dolaşabilmek mümkün değilken, bu sistemler aracılığıyla duyuların yoğun ve güçlü şekilde harekete geçirilmesi vasıtasıyla bu 
ütopik hayali hissedebilmek mümkün olabilmektedir. Bunun yanında askeriye gibi, eğitiminin ciddi süreç gerektirdiği bir alanda, sıfır riskle eğitim yapabilme olanağı gerek ekonomik gerekse de zaman gibi sebeplerden deneyimleyemediğimiz fırsatları bulunduğumuz noktadan, saniyeler içerisinde deneyimleyebilme firsatı sunması açısından bu sistemlerin dünyaya yeni pencere açtı̆̆ı söylenebilir. Engelli bireylere sunulan gerçekçi deneyim firsatları da üzerinde durulacak bir diğer nokta olarak öne çıkmaktadır. Genel olarak sanal gerçeklik sistemlerinin eğlenceli oluşu, zaman, mekân avantajı sağlaması ve pratik olmasının güçlülüğüne dair öne çıkan özellikleri olduğu söylenebilir. Bunların yanı sıra, günümüzün en önemli olgularından biri olan spor ile Metaverse evreninin ilişkisini ele almak da önem arz etmektedir.

\section{TARTIŞMA}

Metaverse kavramının dünyaya sunduğu ikincil ve ikiz gerçeklik olanaklarının, spor gibi günümüzün en önemli olgularından birinden azade olmasını da mümkün kılmamaktadır. Sporda insanların katılımı çeşitli şekillerde olmaktadır. Spor endüstrisinde bireyler sporcu, yönetici, antrenör, hakem, seyirci gibi çeşitli roller alabilmektedir. Sporun grift yapısında bireylerin aldığı görevlerin ifası ve katılımı organizasyonun başarısında en önemli etmenlerin başında gelmektedir. Bu açıdan bakıldığında, sporcunun performansına yönelik katkılar, yöneticinin görevini layıkıyla yerine getirebilmesi, hakemlerin daha doğru kararlar verebilmesi, seyircilerin müsabaka ortamında bulunamadığ durumlarda oradaymışçasına yer alabilmesine yönelik geleneksel yöntemlerden farklı bir pencere Metaverse evreninde sunulabilmektedir. Çalışmanın devamında Metaverse evreninde spora katılım, sporcu, yönetici, hakem ve seyirci boyutundan ele alınmıştır.

\section{Metaverse Evreninde Sporcu Olmak}

Metaverse ve sunduğu imkanların sporculara hangi boyutta faydalı olabileceğine yönelik bilimsel çalışmalar genellikle performans üzerine yoğunlaşmaktadır. Bununla birlikte sporda beceri öğrenimi, teknik ve taktik çalışmalar, genel sağlık için egzersize yönelik uygulamalar da sürdürülmektedir.

Wood ve diğerlerinin (2021) çalışmasında, 17 futbol sporcusu için sanal ortamda tam sürükleyici sanal gerçeklik sistemleri vasıtasıyla dahil olunan antrenman drilleri hazırlanmıştır. Sanal ortamda çalışmaya dahil olan sporcuların süreç sonunda motor performanslarında ve beceri gelişiminde olumlu sonuçlar aldığı sonucuna ulaşılmıştır. Peter Le Noury ve diğerlerinin (2021) çalışmasında tenis sporcularının sanal dünyada katılım sağladıkları tenis ortamıyla gerçek dünyadaki pozisyonları, vuruş stilleri ve adımlamaları karşılaştırılmıştır, sporcuların sanal dünyadaki reaksiyonları ile gerçek dünyadaki reaksiyonları arasında minimum farklar dışında bir fark tespit edilmemiştir. Bunun yanında aynı çalışmada, sporcuların gerçek dünyadaki tenis müsabakalarına hazırlanmalarına olanak sağlayabilecek nitelikte bir ortam sunduğunu da ifade etmişlerdir. Harris ve diğerlerinin (2021) çalışmasında sanal ortamlarda golf sporuna yönelik egzersizlerin gerçek dünya ile farklar içerdiğine ancak performans açısından olumlu katkılar sunulduğuna dikkat çekmişlerdir. Sean ve diğerlerinin (2021) sanal ortamda çalışanlar ve gerçek ortamda çalışanlar olarak iki gruba ayırarak, tek ayak sıçramaya yönelik yaptıkları çalışmada sanal ortamda çalışan kişilerin daha iyi performans 
sergilediklerine yönelik anlamlı farka ulaşmışlardır. Baños ve diğerlerinin (2016) aşırı kilolu çocukların egzersize katılımındaki psikolojik faktörleri ele aldıkları çalışmalarında, söz konusu çocukların sanal dünyada daha çok eğlendikleri ve katılım sağladıklarına yönelik sonuçlara ulaşılmıştır. Hoffman ve diğerlerinin (2014) kürek sporcularının yarış stratejilerinin ve enerji yönetimlerinin geliştirilmesine yönelik sanal dünya kullanım tabanlı modelinde katılımcıların gelişim sağladıklarına dair sonuçlara ulaşmışlardır.

Bahsi geçen çalışmalarda, sporcuların Metaverse evreninde sanal dünyalar aracılığıyla katılım sağlamalarının çeşitli faydalar sağlayabildiği ifade edilmiştir. Sporcuların bu evrende, beceri öğrenimi, performans geliştirme, psikolojik hazırlık, müsabaka ortamını önceden hissedebilme olană̆ıla kaygı düzeylerini optimal seviyeye getirebilmeleri, sporcu yaralanması ve rehabilitasyon döneminde bulundukları ortamda egzersize katılım sağlayabilme, antrenman tesislerinin çeşitli nedenlerle işlerliğini kaybettiği dönemlerde telafilerini gerçekleştirebilme gibi birçok boyutta katkı sağlayabileceği söylenebilir. Gerçek dünyadaki spora ve antrenmana katılımın öneminin halen günümüzdeki en önemli mesele olduğunun altını çizerek, sporcuya ek katkı sağlayabilecek bir yöntemin varlığının da günümüz ve gelecekte bir aktör olarak yer aldığını ifade edebiliriz. Metaverse yatırımlarının arttığı günümüzde, bu sistemlerin tüm bireylerin satın alabileceği fiyatlarda olabilmesi, teknolojisinin ve gerçeklik hissinin yeni patentlerle güçleniyor olması, gelecek dönemde sporcuların daha gerçekçi biçimde antrenman yapabilmesine olanak sağlayacak nitelik sergileyeceği söylenebilir. Kayak yapma imkânı olmayan bir bölgede yaşayan bir kişinin kayak sporuyla kıta ya da ülke değiştirmeden tanışabilmesi, havuzu ya da denizi olmayan bir bölgede yüzme deneyimi sunabilmesi, binlerce kilometre ötedeki sporcuların birlikte antrenman yapabilmesine yönelik altyapısıyla, bu evrenin teknoloji çağında spor ve sporcuya farklı imkanları sunduğunu ve sunmaya devam edebileceğine yönelik bir çıarımdan söz edebiliriz.

Sanal ikiz ortamdan fazlasını ifade eden Metaverse kavramındaki spor ve egzersiz olanakları incelendiğinde, Steam VR ve Viveport kütüphanelerinde birçok uygulama olduğunu görebilmekteyiz. Masa Tenisi, futbol, basketbol, tenis gibi birçok branşta kişilerin avatarları aracıllğıyla birbirleriyle iletişime geçip, çeşitli aktiviteleri yapabilmelerine olanak sağlayan bir altyapının mevcuditeyi de söz konusudur. İnternetle donatılmış, sanal bir dünyada varlığı dijitalize eden bir yapının içerisinde spor ve egzersiz ile yer alabilmek günümüzde mümkün durumdadir.

\section{Metaverse Evreninde Spor Yöneticisi Olmak}

Sporun idame ettirilmesinde en önemli görevlerden biri de şüphesiz spor yöneticilerine aittir. Özellikle Covid-19 pandemisi döneminde en büyük zararı gören sektörlerden biri de spor olmuştur. Öyle ki Olimpiyatlar gibi dünyanın en büyük organizasyonundan, Tour de France'a, Euro 2020 Futbol Şampiyonası'ndan yerel müsabakalara kadar neredeyse tüm branşlarda tüm organizasyonlar iptal edilmiş ve ertelenmiştir (Grix, Brannagan, Grimes, \& Neville, 2021). Devasa bir ekonomik sisteme sahip sporun ve paydaşlarının bu süreçte azımsanmayacak derecede yönetsel faaliyete ihtiyaç duyduğu bir süreç olmuştur. Uluslararası bir organizasyonun planlanması, programlanması ve organize edilmesinin ciddi bir iş yüküne neden olduğu düşünüldüğünde tüm organizasyonların yeniden ele alınarak dar bir tarih aralığında devam ettirilmesi ve gerçekleştirilmesi ciddi bir yönetim emeğini de beraberinde 
getirmiştir. Bu süreçte iptal edilen birçok organizasyonun sanal olarak, sporcuların evlerinden katılacak şekilde organize edilmesine yönelik faaliyetler de düzenlenmiştir. Bunlara örnek olarak 2020 Sanal Tour de France (Tour de France Virtuel), motor sporlarında dünyanın önde gelen pilotlarının Formula E simülasyonunda birlikte yarışmaları, 19-20 Eylül 2020 tarihlerinde İstanbul'da organize edilen sanal maraton gibi organizasyonlar verilebilir (Grix vd., 2021). Bu süreçte egzersizden ve spordan kopmamak adına alınan bu yönetsel kararlar, spor yöneticilerinin spora ve sporcuya duyduğu sorumluluk duygusunu ifade etmektedir. Alışmış olduğumuzun düzenin dışına bizleri iten pandeminin spora verdiği zararları minimize etme amacı güden bu yönetsel reaksiyonların sanal dünyalar ile mümkünleştiğini de ifade etmek gerekir. Buradan hareketle, spor yöneticilerinin sanal dünyada sporun organizasyonuna yönelik gelecek vizyonuna sahip olmasına yönelik gereklilikten söz edilebilir.

\section{Metaverse Evreninde Antrenör Olmak}

Sporda performansın en önemli görevlerden biri antrenörlere aittir. Sporda artan rekabet ve ekonomik güç, beraberinde sporcu performansının sürekli olarak artırılmasına yönelik önlemleri de şart k1lmaktadır. Öyle ki, günümüzde etkin ve etkili antrenman yöntemlerine yönelik bir gün içerisinde onlarca akademik yayın çıkmakta mevzubahis yöntemler sürekli olarak geliştirilmeye çalışılmaktadır. Teknoloji çağında antrenmanlarda teknolojiden sürekli olarak faydalanıldığı bir dönemi gözlemlemekteyiz. Giyilebilir teknolojiler, simülasyonlar, reaksiyon antrenmanlarında kullanılan çeşitli materyaller gibi birçok teknolojik donanımı birçok spor branşında saymak mümkündür. Sanal gerçeklik ve Metaverse evreninde de buna uygun örnekler bulmak pek tabii mümkündür. Ancak, teknolojide en son gelişen araçlar ve platformlar olan bu sistemlerin, günümüzde diğer teknolojilere nazaran daha az kullanıldığı da bilinmektedir. Sanal gerçeklik ve Metaverse sistemlerinin antrenman yöntemleri açısından kullanıldığı akademik çalışmalar ve programlar mevcuttur.

Gürbüz (2021), küçük yaş grup sporcularının futbolda kafa vuruşunun olası sağlık sorunlarına sebebiyet verebildiği, bu nedenle bazı ülkelerde bu yaş grubundaki sporcuların kafa vuruşu yapmasının yasak olmasından hareketle yürüttüŭgü çalışmasında Rezzil adlı futbol antrenman uygulamasını kullanmıştır. Çalışmasında küçük yaş gruplarında topun kafayla temasını ortadan kaldırarak, alternatif bir yöntemle kafa vuruşu tekniği üzerine antrenmanlar yapabilme olanağı sağlamıştır. ABD'nin en büyük beyzbol kulüplerinden biri olan New York Yankees, WIN Reality Games uygulaması aracılı̆̆ıla çeşitli antrenmanlarını sanal gerçeklik sistemleri aracılı̆̆ıla sürdürdüğüne dair açıklama yapmıştır. Bunun yanında çok sayıda sporcuyla, çok sayıda taktik öge barındırmasıyla bilinen Amerikan Futbolu branşında, antrenmanların daha etkin olması amacıyla STRIVR uygulamasını birçok NFL takımının kullandığı bilinmektedir (Carter \& Egliston, 2021). Cannavo ve diğerlerinin (2017) çalışmasında basketbolda taktik çalışmalarda VR Playbook uygulamasının etkililiğine dair yaptıkları çalışmada da kullanım alanına dair farklı bir örnek sergilenmektedir. Bu boyutta birçok örneğin olduğu, çeşitli denemelerin birçok spor branşında sürdürüldüğü gözlemlenmektedir. Metaverse evreninde farklı yer, zaman ve mekânda bulunan antrenör ve sporcuların birlikte taktik ve teknik varyasyonlar çalışabilecekleri olanaklar bir avantaj olarak değerlendirilebilir. Bunun yanında antrenman saatlerinin dışında sporcuların daha eğlenceli ve motive edici özelliği olan sistemler aracılığıyla çalışmasına yönelik firsatlar sunulabilmektedir. Örneğin, bir altyapı basketbol 
sporcusunun ABD'deki basketbol kampına katılabilmesi gerek ekonomik gerekse de zaman açısından kolayca erişebilecek bir firsat olmamaktadır ancak bu sistemlerin daha gerçekçi modellerinin olası gelişimi, bu tür katılım imkanlarını kullanıcılarına sunabilecektir. Bunun yanında simüle edilmiş ortamlarda hatanın telafisinin sonsuz sayıda olabilmesi, farklı sporcuların özelliklerinin simüle edilebilmesi yoluyla doğrudan rakibe göre antrenman yapabilme olanağı da bir diğer gelecek vizyonu olarak değerlendirilebilir.

\section{Metaverse Evreninde Hakem Olmak}

Spor dünyasında en çok konuşulan ancak en az konuşan figürlerden biri olan hakemlerin oyunun adaletine dair sorumlulukları yaşadıkları kaygı ve stresi de artırmaktadır. Bu sebeple hakemlerin mentörlerle çalışmalar yaptıkları, kendilerinin daha hazır tutulması amacıyla çeşitli yöntemler uygulandığı bilinmektedir. Sanal ortamların da bu yöntemlerden biri olarak kullanıldı̆̆ına dair örnekler mevcuttur. Akiyama ve diğerlerinin (2020) çalışmasında futbol hakemlerinin deneyimlerini artırmaya yönelik sanal gerçeklik sistemlerinin kullanıldığı bir örnek mevcuttur. Bunun yanı sıra, Kittel ve diğerlerinin (2021) Avustralya Futbolu hakemlerine yönelik hazırladıkları, 360 derece sanal gerçeklik destekli video tabanlı eğitim sürecinde, hakemlerin karar verme yetilerinin geliştirilmesine yönelik çalışma yürütülmüş̧ür. Süreç sonunda, geleneksel yöntemler kullanılan kontrol grubuna göre psikolojik uygunluk ve keyif alma açısından deney grubu daha yüksek skorla elde etmiştir. Hakemlerin baskı düzeyi yüksek bir meslek icra ettikleri düşünüldüğünde, Metaverse evreninde katılım sağlayabilecekleri gerçekçi simülasyonların gerek psikolojik hazır olma gerekse de karar verme becerilerine yönelik eğitim firsatları bulabilecekleri söylenebilir.

\section{Metaverse Evreninde Spor Seyircisi Olmak}

1990'lı y1llarda seyirci ve taraftar olmanın tüketim skalasında en önemli unsur bilet satın alıp müsabakalara katılmakken günümüzde sporun dev bir endüstri olmasıyla ürün yelpazesi de iyice genişlemiştir. Özellikle 2000'li yıllarla birlikte spor müsabakalarının ücretli yayınlarla verilmesi, lisanslı ürün mağaza zincirlerinin yaratılması, sezonluk kombine bilet satı̧̧ları gibi ürün yelpazesini genişletici faaliyetler düzenlenmektedir. Günümüzde sanal dünyaların önem kazanmasıyla birlikte, Blockchain tabanlı sportif yatırımların da arttı̆̆ görülmektedir ( $\mathrm{Li}, \mathrm{Kim}$, \& Ding, 2021). Galatasaray, Fenerbahçe, Karşıyaka Spor Kulübü gibi 100 ylldan fazla tarihi olan spor kulüplerinin fan tokenları ticari bir meta olarak sunarak gelir elde etmesi, Galatasaray'ın Shirtum ortaklığıyla NFT marketi açması Metaverse ortamında spor kulüplerinin varlığına yönelik güçlü ve ciddi örnekler olduğu söylenebilir (Findikli \& Saygin, 2021). Geleneksel olarak spor müsabakalarına katılım sağlamanın yanı sıra Metaverse evreninde Blockchain tabanlı NFT'lere sahip olabilmek, sanal stat turu, sanal müze turu gibi etkinliklere katılabilmek, aynı takım taraftarlarını sanal ikiz bir ortamda avatarları aracılığıyla zaman ve mekân fark etmeksizin buluşturabilmek günümüzde uygulanmakta olan yöntemlerdir (Kiong, 2021; Wang, Li, Wang, \& Chen, 2021). Burada bir parantez müsabakalara sanal gerçeklik sistemleriyle katılım noktasında açmak gerekmektedir. Spor müsabakalarının TV'de $4 \mathrm{~K}$ ve UHD olarak yayınının verildiği düşünülerek, bu sistemlerin grafik kalitesinin gelecekte artması durumunda, kullanıcıların dünyanın dört bir yanındaki salon ya da statlarda oradalık yaşayarak katılabilmesinin geleceğe dair bir aşama olduğunu söylemek gerekir. 


\section{SONUÇ}

Teknolojinin dünyamızı hızla yenilediği ve değiştirdiği herkes tarafından paylaşılan bir gerçekliktir. Bu hıza ve gelişime ayak uydurabilmek, çağa ayak uydurabilmenin de öncülü olarak kabul görmektedir. Covid-19 pandemisiyle birlikte birçok insanın tanıştı̆̆ 1 uzaktan eğitim, sanal gerçeklik gibi kavramların aslında uzun süreli tarihsel bir aşama kaydettiğini, bu tür bir teknolojik çağın ayak seslerinin öteden beri geldiğini söylemek mümkündür. Bugün güçlü yatırımlarla birlikte adı daha da duyulmaya başlanan Metaverse kavramının, sporda da çeşitli izdüşümleri olduğunu ortaya koyan bu çalışma, gelecekte olabilecek değişim ve gelişimlere spor dünyasındaki paydaşların dikkatini çekmeyi amaçlamaktadır. Metaverse kavramının spor endüstrisi ve paydaşlarınca organizasyonel faaliyetlere dahil edildiği, bu konuda çeşitli çalışmaların sürdüğü, yeni antrenman yöntemleri içerisinde yer alabildiği, hakem eğitiminde, taktik ve teknik çalışmalarda, spor pazarlamasında, rehabilitasyon sürecinde, beceri öğrenmede ve diğer birçok alanda spor ile gitgide yakınlaşan bir ilişki kurduğu söylenebilir.

Sonuç olarak; Metaverse evreninde sporun ve egzersizin önemli bir yere sahip olduğu, alandaki gelişimin spora ve paydaşlarına çeşitli olanaklar sunabileceği ifade edilebilir.

Yayın Etiği: $\mathrm{Bu}$ çalışmanın hazırlanma ve yazım sürecinde "Yükseköğretim Kurumları Bilimsel Araştırma ve Yayın Etiği Yönergesi” kapsamında bilimsel, etik ve alıntı kurallarına uyulmuş olup; toplanan veriler üzerinde herhangi bir tahrifat yapılmamış ve bu çalışma herhangi başka bir akademik yayın ortamına değerlendirme için gönderilmemiştir.

Çıkar Çatışması: Çalışmada herhangi bir çıkar çatışması olmadığını beyan ederim.

Araştırmacıların Katkı Oranı Beyanı: Yazar çalışmanın tamamından sorumludur. 


\section{KAYNAKLAR}

Akiyama, H., Tanaka, Y., Saito, R., \& Aramaki, S. (2020, December). An Experience System of Soccer Referee Using Immersive Virtual Reality. In 2020 Joint 11th International Conference on Soft Computing and Intelligent Systems and 21st International Symposium on Advanced Intelligent Systems (SCIS-ISIS) (pp. 1-4). IEEE.

Arıcı, V. A. (2013). Fen eğitiminde sanal gerçeklik programları üzerine bir çalışma:" Güneş sistemi ve ötesi: Uzay bilmecesi" ünitesi örneği. Adnan Menderes Üniversitesi Sosyal Bilimler Enstitüsü

Banos, R. M., Escobar, P., Cebolla, A., Guixeres, J., Alvarez Pitti, J., Lisón, J. F., \& Botella, C. (2016). Using virtual reality to distract overweight children from bodily sensations during exercise. Cyberpsychology, Behavior, and Social Networking, 19(2), 115-119.

Bec, A., Moyle, B., Schaffer, V., \& Timms, K. (2021). Virtual reality and mixed reality for second chance tourism. Tourism Management, 83, 104256.

Borges, M., Symington, A., Coltin, B., Smith, T., \& Ventura, R. (2018). HTC vive: Analysis and accuracy improvement. 2018 IEEE/RSJ International Conference on Intelligent Robots and Systems (IROS), 2610-2615. IEEE.

Cannavò, A., \& Lamberti, F. (2021). How Blockchain, Virtual Reality, and Augmented Reality are Converging, and Why. IEEE Consumer Electronics Magazine, 10(5), 6-13. https://doi.org/10.1109/MCE.2020.3025753

Cannavo, A., Musto, M., Prattico, F. G., Raho, F., \& Lamberti, F. (2018). A participative system for tactics analysis in sport training based on immersive virtual reality. In Proceeding of the 4th workshop on Everyday Virtual Reality (WEVR 2018)-25th IEEE conference on Virtual Reality and 3D User Interfaces (pp. 1-4).

Carter, M., \& Egliston, B. (2021). What are the risks of Virtual Reality data? Learning Analytics, Algorithmic Bias and a Fantasy of Perfect Data. New Media \& Society. https://doi.org/10.1177/14614448211012794.

Cochran, S. M., Aiken, C. A., Rhea, C. K., \& Raisbeck, L. D. (2021). Effects of an external focus of attention and target occlusion on performance in virtual reality. Human Movement Science, 76, 102753. https://doi.org/10.1016/j.humov.2021.102753

Craig, A. B., Sherman, W. R., \& Will, J. D. (2009). Chapter 6- Education Applications. In A. B. Craig, W. R. Sherman, \& J. D. Will (Eds.), Developing Virtual Reality Applications (pp. 189-237). Morgan Kaufmann. https://doi.org/10.1016/B978-0-12-374943-7.00006-9

Dempsey, P. (2016). The teardown: HTC Vive VR headset. Engineering \& Technology, 11(7-8), 80-81.

Dionisio III, J. D. N. (n.d.). WGB and Gilbert, R. 2013. 3D Virtual worlds and the metaverse: Current status and future possibilities. ACM Computing Surveys, 45, 1-38. https://doi.org/10.1145/2480741.2480751

Elmqaddem, N. (2019). Augmented Reality and Virtual Reality in Education. Myth or Reality? International Journal of Emerging Technologies in Learning (iJET), 14(3), 234-242. https://doi.org/10.3991/ijet.v14i03.9289

Emmelkamp, P. M., \& Meyerbröker, K. (2021). Virtual reality therapy in mental health. Annual Review of Clinical Psychology, 17, 495-519. https://doi.org/10.1146/annurev-clinpsy-081219-115923

Findikli, S., \& Saygin, E. P. (2021). Müsteri Vatandaslik Baglaminda Taraftar Tokenlari. Third Sector Social Economic Review, 56(1), 57-71.

González-Zamar, M.-D., \& Abad-Segura, E. (2020). Implications of virtual reality in arts education: Research analysis in the context of higher education. Education Sciences, 10(9), 225. https://doi.org/10.3390/educsci10090225 
Grix, J., Brannagan, P. M., Grimes, H., \& Neville, R. (2021). The impact of Covid-19 on sport. International Journal of Sport Policy and Politics, 13(1), 1-12.

Gürbüz, E. (2021). 12-13 yaş çocuk futbolcularda sanal gerçeklik antrenmanının kafa vuruşu becerisine etkisi. Yüksek Lisans Tezi, Manisa Celal Bayar Üniversitesi, Sağlık Bilimleri Enstitüsü.

Hamilton, D., McKechnie, J., Edgerton, E., \& Wilson, C. (2021). Immersive virtual reality as a pedagogical tool in education: a systematic literature review of quantitative learning outcomes and experimental design. Journal of Computers in Education, 8(1), 1-32. https://doi.org/10.1007/s40692-020-00169-2

Harris, D. J., Buckingham, G., Wilson, M. R., Brookes, J., Mushtaq, F., Mon-Williams, M., \& Vine, S. J. (2021). Exploring sensorimotor performance and user experience within a virtual reality golf putting simulator. Virtual Reality, 25(3), 647-654.

Hoffmann, C. P., Filippeschi, A., Ruffaldi, E., \& Bardy, B. G. (2014). Energy management using virtual reality improves 2000-m rowing performance. Journal of Sports Sciences, 32(6), 501-509.

Jeon, H. J., Youn, H. C., Ko, S. M., \& Kim, T. H. (2021). Blockchain and AI Meet in the Metaverse. In Blockchain Potential in AI. IntechOpen.

Kalkan, N. (2020). Virtual reality and instructional design: Virtual reality assisted instructional design model in skill learning. Akademisyen Kitabevi.

Kavanagh, S., Luxton-Reilly, A., Wuensche, B., \& Plimmer, B. (2017). A systematic review of Virtual Reality in education. Themes in Science and Technology Education, 10(2), 85-119.

Kiong, L. V. (2021). DeFi, NFT and GameFi Made Easy: A Beginner's Guide to Understanding and Investing in DeFi, NFT and GameFi Projects. Liew Voon Kiong.

Kittel, A., Larkin, P., Elsworthy, N., \& Spittle, M. (2021). Transfer of $360^{\circ}$ virtual reality and match broadcast video-based tests to on-field decision-making. Science and Medicine in Football, 5(1), 79-86.

Le Noury, P., Buszard, T., Reid, M., \& Farrow, D. (2021). Examining the representativeness of a virtual reality environment for simulation of tennis performance. Journal of Sports Sciences, 39(4), 412-420.

Lee, H. T., \& Kim, Y. S. (2018). The effect of sports VR training for improving human body composition. EURASIP Journal on Image and Video Processing, 2018(1), 1-5.

Lee, L. H., Braud, T., Zhou, P., Wang, L., Xu, D., Lin, Z., ... \& Hui, P. (2021). All one needs to know about metaverse: A complete survey on technological singularity, virtual ecosystem, and research agenda. arXiv preprint arXiv:2110.05352.

Li, Y., Kim, K., \& Ding, Y. (2021). Research on Optimization of Blockchain Network and Data Communication in the Ecological Structure of Sports Industry. Wireless Communications and Mobile Computing, 2021, 3523681. https://doi.org/10.1155/2021/3523681

Ma, M., \& Zheng, H. (2011). Virtual reality and serious games in healthcare. In Advanced computational intelligence paradigms in healthcare 6 . Virtual reality in psychotherapy, rehabilitation, and assessment (pp. 169-192). Springer, Berlin, Heidelberg.

Muñoz-Saavedra, L., Miró-Amarante, L., \& Domínguez-Morales, M. (2020). Augmented and virtual reality evolution and future tendency. Applied sciences, 10(1), 322. https://doi.org/10.3390/app10010322

Nevelsteen, K. J. (2018). Virtual world, defined from a technological perspective and applied to video games, mixed reality, and the Metaverse. Computer Animation and Virtual Worlds, 29(1), e1752. https://doi.org/10.1002/cav.1752

Sivunen, A., \& Nordbäck, E. (2015). Social presence as a multi-dimensional group construct in 3D virtual environments. Journal of Computer-Mediated Communication, 20(1), 19-36. 
Smith, M. J., Ginger, E. J., Wright, K., Wright, M. A., Taylor, J. L., Humm, L. B., Olsen, D. E., Bell, M. D., \& Fleming, M. F. (2014). Virtual reality job interview training in adults with autism spectrum disorder. Journal of Autism and Developmental Disorders, 44(10), 2450-2463.

Sparkes, M. (2021). 3D-printed steel bridge takes the load in Amsterdam. New Scientist, 251(3344), 18. https://doi.org/10.1016/s0262-4079(21)01450-0

Stephenson, N. (1992). Snow Crash, Bantam. New York.

Topuz, Y. (2018). Anatomi eğitiminde sanal gerçeklik ve üç boyutlu masaüstü materyallerin akademik başarı ve bilişsel yük açısından karşılaştırılması. Marmara Üniversitesi Eğitim Bilimleri Enstitüsü, İstanbul.

Wang, Q., Li, R., Wang, Q., \& Chen, S. (2021). Non-fungible token (NFT): Overview, evaluation, opportunities and challenges. arXiv preprint arXiv:2105.07447.

Webel, S., Bockholt, U., Engelke, T., Gavish, N., Olbrich, M., \& Preusche, C. (2013). An augmented reality training platform for assembly and maintenance skills. Robotics and Autonomous Systems, 61(4), 398403.

Wijkmark, C., Heldal, I., \& Metallinou, M. (2021). Experiencing Immersive VR Simulation for Firefighter Skills Training. In 18th ISCRAM Conference 913-921. Blacksburg: WiP Paper.

Wood, G., Wright, D. J., Harris, D., Pal, A., Franklin, Z. C., \& Vine, S. J. (2021). Testing the construct validity of a soccer-specific virtual reality simulator using novice, academy, and professional soccer players. Virtual Reality, 25(1), 43-51.

Zuckerberg, M., \& Heath, A. (2021). Mark Zuckerberg on why Facebook is rebranding to Meta. The Verge.

Bu eser Creative Commons Atıf-GayriTicari 4.0 Uluslararası Lisansı ile lisanslanmıştır. 